\title{
Effect of EXAFS on the dosimetric related parameters
}

\author{
Chitralekha Alur, Sharanabasappa Patil, Manjunath Apparao, Basavaraj Kerur ${ }^{*}$
}

Department of Physics, Gulbarga University, Gulbarga, India; 'Corresponding Author: kerurbrk@hotmail.com

Received 4 March 2011; revised 22 March 2011; accepted 27 March 2011.

\begin{abstract}
Mass attenuation coefficients have been measured for rare earth compounds at photon energies $8.041,8.907$ and $13.347 \mathrm{keV}$. The measured values are compared with theoretical calculations. The agreement between experiment and theory is more than the experimental error when the incident photon energy is around the edge of the element present in the compound and agreeing with the theoretical values elsewhere. The difference in agreement between the theoretical values and experimental values is attributed to the EXAFS effects on the mass attenuation coefficient values.
\end{abstract}

Keywords: Mass Attenuation Coefficient; Near Absorption Edge; Cross Section; Resonance Raman Scattering; EXAFS

\section{INTRODUCTION}

In medical physics, it is important to measure the amount of radiation delivered by the ionizing radiation, in composite substances. For photon interactions in composite substances a single number cannot represent the atomic number uniquely across the entire energy region. This number in composite substances is called the effective atomic number and it varies with energy and is denoted here by $Z_{\text {eff. }}$ On the other hand, the concept of z-dependence of photon attenuation has led to many applications in radiation studies. For example precise knowledge of effective atomic numbers is very important in medical radiation dosimetry and medical imaging, where the cross-sectional anatomy is generated by computer-assisted tomography (CAT) scans [1]. It is a common practice to verify the validity of calculation algorithms by comparing the generated doses with the measured doses in tissue equivalent phantom substances. Similarly, tissue-equivalent phantoms are specifically designed to study the image quality and performance of the CAT scanners. In both instances, a precise knowledge of the effective atomic number and electron density of the composite substances is necessary in the low energy region and have proved to be a convenient parameter for interpretation of $\mathrm{x}$-ray attenuation by a complex medium like a biological tissue and particularly for the calculation of dose in radiography and radiation dosimetry etc.

The $\mathrm{x}$-ray mass attenuation coefficient, $\mu / \rho$, for any material are usually estimated from Bragg's additivity law or more commonly called mixture rule. Thus $\mu / \rho$ for any chemical compound/material is given by

$$
\mu / \rho=\sum \omega_{i}(\mu / \rho)_{i},
$$

where $(\mu / \rho)_{i}$ is the mass attenuation coefficient of the $i^{\text {th }}$ element and $\omega_{i}$ is the fraction by weight of the $i^{\text {th }}$ element. For a compound/material with chemical formula $\left(Z_{1}\right)_{a 1},\left(Z_{2}\right)_{a 2}, \cdots,\left(Z_{n}\right)_{a n}$ the weight factor for the $i^{\text {th }}$ element is given by

$$
\omega_{i}=\left\{\left(a_{i} A_{i}\right) /\left(\sum a_{i} A_{i}\right)\right\},
$$

where $A_{i}$ is the atomic weight of the $i^{\text {th }}$ element. Hence an attempt has been in this regard to determine the $\mu / \rho$ of x-rays for the dosimetric materials (sulphides of $\mathrm{Mg}$, $\mathrm{Ca}, \mathrm{Mn} \mathrm{Fe}$ and $\mathrm{Zn}$ elements) and then determined the $Z_{\text {eff }}$ of these materials by LSF method from $\ln (\mu / \rho)$ Vs $\ln Z$ graph. These values are compared with the theoretical values. The so determined value of $Z_{\text {eff }}$ has been used in the expression

$$
N_{e}=N_{A} Z_{\text {eff }} \sum n_{i} / A
$$

to calculate the electron density.

In the present measurement the validity of Bragg's law is studied for rare earths compounds of L edges. The selection of the compounds was dictated by the incident photon energy and the by the limitations of our experimental facilities such that thin foils from the compounds. The former factor determined the region of the atomic numbers, wherein the absorption edges energy are close to the incident photon energy, and the latter determined the selection of particular compounds in this region. We have used ${ }^{241} \mathrm{Am}$ (VEC) radioactive $\mathrm{x}$-ray source with weighted average energy of $K_{\alpha}$ of 8.041 and $13.347 \mathrm{keV}$ energy respectively and the compounds of rare earths 
having the elements in the region $57 \leq Z \leq 70$.

\section{EXPERIMENTAL ARRANGEMENT}

The good-geometry experimental arrangement used for the determination of the mass attenuation coefficient is similar to the one described in detail by us earlier [2]; and is shown in Figure 1. Briefly, photons from a variable energy $\mathrm{x}$-ray source $\mathrm{S}$ passed through a collimator $\mathrm{C} 1$ and were incident on the specimen $\mathrm{A}$ in the form of a thin foil kept normal to the photon beam. The transmitted beam passed through another collimator C2 and reached a HPGe x-ray detector system D. The transmitted photon spectrum was recorded using a PC based multichannel analyzer.

The collimators $\mathrm{C} 1$ and $\mathrm{C} 2$ were $40 \mathrm{~mm}$ thick lead discs that collimated respectively the incident and transmitted beam to $6 \mathrm{~mm}$ dia. The scatter acceptance angle equal to the sum of the incident beam divergence and acceptance angle at the detector is found to be $\leq 3^{\circ}$ degrees. This thickness of the collimator would reduce the intensity of scattered photons of $300 \mathrm{keV}$ by a factor of $10^{7}$.

The variable energy x-ray source consisted of $10 \mathrm{mCi}$ (370 MBq) ${ }^{241} \mathrm{Am}$ as the primary source of excitation radiation Copper and Rubidium targets were selected to produce fluorescence $\mathrm{x}$-ray with characteristic energy of the target i.e., 8.041 and $13.347 \mathrm{keV}$. The inner bremsstrahlung intensity was found to be negligible compared to the x-ray intensity in the region of interest. No noticeable impurities were found in the source spectra.

The Dosimetric compounds viz., rare earth sulphate compounds of $99.5 \%$ purity were obtained from SD fine chemicals Mumbai, India. The Dosimetric samples of required thickness in the range of 10 to $30 \mathrm{mg} / \mathrm{cm}^{2}$ were prepared by using blotting paper technique. The area density (mass per unit area) of each foil sample was determined by weighing it using a single pan electronic balance with an accuracy of $0.01 \mathrm{mg}$ and measuring its dimensions using a traveling microscope with an accuracy of $0.001 \mathrm{~cm}$. Thus the measured areal density expressed in $\mathrm{mg} / \mathrm{cm}^{2}$ had an uncertainty.

The x-ray spectrometer consist of an n-type x-ray detector of area $500 \mathrm{~mm}^{2} \times 100 \mathrm{~mm}$ thick High Purity Germanium detector connected to DSA-1000 16K MCA. The spectrometer was operated by Genie 2000 software. The detector is connected directly to a preamplifier through a cooled FET device, and mounted over a rigid cryostat with Dewar to accommodate the liquid Nitrogen. DSA-1000 allows independent of rise time and flat top selection, which optimizes the performance of the detector, spectral energy, count rate and resolution. HPGe detector along with DSA-1000 has resulted with a resolution of $191 \mathrm{eV}$ at $5.895 \mathrm{keV}$ as against $200 \mathrm{eV}$ by the

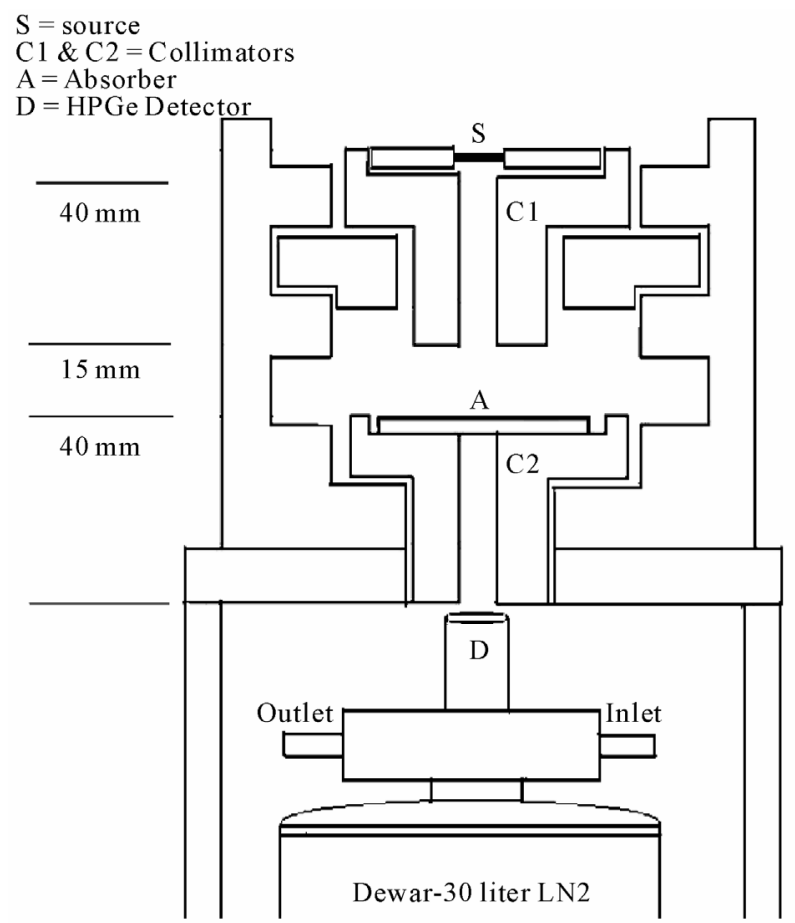

Figure 1. Experimental arrangement.

manufacturers.

The advantage of the high resolution HPGe detector system is its wide operating energy range from $3 \mathrm{keV}$ to $500 \mathrm{keV}$ and very good energy resolution, ${ }^{241} \mathrm{Am}$ source with different target the photo peaks of $K_{\alpha}$ and $K_{\beta}$ of were well resolved. As a result of this, the energies of the photons with degrade in energy due to small angle scattering and multiple scattering, if at all present, could be observed in the source spectrum, but in the present case no such degraded photo peak were observed except the $K_{\beta}$ and $K_{\beta}$ and gamma photons of ${ }^{241} \mathrm{Am}$ source. Therefore, $\mu / \rho$ value obtained in such configuration is purely corresponding to the respective energies only i.e., $K_{\alpha}$ and $K_{\beta}$ gamma-rays.

The error involved in each measurement is taken care by following the procedure counting time conditions as stated in [3]; viz., background to signal background to foil thickness and signal to foil thickness, systematic errors due to the detection of forward scattered radiation, beam hardening when higher atomic number absorber is used. Ray-sum method has been adopted in the present measurement for calculation for the random errors which arises from all aspects of the measurement, further is has also suggested a method for the calculation called the ray-sum error. In the present measurements ray-sum method is applied to all the observation since the random errors arises from all aspects of measurement, in the exponential law of attenuation. The errors are calculated by using the formula provided by [4]; and are presented in 
the tables.

No dead time corrections are found for photon intensity measurements considered area under photopeak. However, in the present case we have selected the live time of the MCA for sources. With these conditions, the transmitted intensity of $\mathrm{X}$-rays for various combinations of specimen thickness is recorded and corrected for background intensity [5,6]. A plot of logarithm of transmission as a function of specimen thickness yielded a straight line for the entire transmission region, verifying the validity of the Beer-Lambert's law. This is confirmed for different materials also.

\section{RESULTS AND DISCUSSION}

The plots of the logarithm of transmitted intensity versus specimen thickness were linear for all the samples and the $\mu / \rho$ was obtained from the plots by linear regression over the $50 \%-2 \%$ transmission range [7]. The $\mu / \rho$ obtained for the all dosimetric compounds at three different photon energies are presented in Table 1.

The theoretical estimated errors are between $1 \%$ and $2 \%$ taken from the WinXCom. The error involved in over all experimental values is about $2 \%$ to $3 \%$ for the dosimetric samples.

In Table 1 the second column represent $L$ shell Bind- ing energies $E_{L}$ of the element present in the compound, third column represents difference, $\left(E_{x}-E_{L}\right)$ between the incident photon energy $E_{x}$ (viz., 8.041, 8.907 and 13.347 $\mathrm{keV}$ ) and L shell binding energy $E_{L}$. The fourth column represents experimental $\mu / \rho$ value, fifth column represents theoretical $\mu / \rho$ value (WinXom), and the percentage difference (PD) between experiment and theory is given in the last column of the table. The positive and negative sign indicates that the interested element L shell binding energy is above or below the incident photon energy, and the binding energies are taken from Kortright et al. [8].

Further from Table 1, there is a good agreement between theoretical and experimental value for all the compounds at $13.347 \mathrm{keV}$, it is confirmed fact that when the incident photon energy is far away from the absorption edge, there is good agreement between experimental value with theoretical value within $4 \%$. On the other hand, the same mixture rule can't be applicable for Neodymium and Europium sulphate with $\mathrm{E}_{\mathrm{x}}-\mathrm{E}_{\mathrm{L}}$ ranging from 0.915 to 0.429 . Here, the experimental value deviates from the theoretical value by $-7.7 \%$ and $-16.2 \%$ and next, in case of Europium and Terbium sulphate at $8.907 \mathrm{keV}$ with $\mathrm{E}_{\mathrm{x}}-\mathrm{E}_{\mathrm{L}}$ in range from 1.295 and $0.655 \mathrm{keV}$ for $L$ edge shows a deviation in the mass attenuation

Table 1. Experimental and theoretical mass attenuation coefficient.

\begin{tabular}{|c|c|c|c|c|c|}
\hline \multirow{2}{*}{ Name of the Sample } & \multirow{2}{*}{$E_{L}$ binding energy in $\mathrm{keV}$} & \multirow{2}{*}{$\Delta E=E_{x}-E_{L}(\mathrm{keV})$} & \multicolumn{2}{|c|}{ Mass attenuation coefficient $\left(\mathrm{cm}^{2} / \mathrm{kg}\right)$} & \multirow{2}{*}{ P.D in $\%$} \\
\hline & & & Expt. value & WinXcom & \\
\hline \multicolumn{6}{|c|}{$E_{x}=8.041 \mathrm{keV}$} \\
\hline $\mathrm{Nd}_{2}\left(\mathrm{SO}_{4}\right)_{3} \cdot 8 \mathrm{H}_{2} \mathrm{O}$ & 7.126 & 0.915 & $165.3 \pm 1.7$ & 179.2 & -7.7 \\
\hline $\mathrm{Eu}_{2}\left(\mathrm{SO}_{4}\right)_{3} \cdot 8 \mathrm{H}_{2} \mathrm{O}$ & 7.612 & 0.429 & $150.5 \pm 1.5$ & 179.6 & -16.2 \\
\hline $\mathrm{Tb}_{2}\left(\mathrm{SO}_{4}\right)_{3} \cdot 8 \mathrm{H}_{2} \mathrm{O}$ & 8.252 & -0.211 & $152.8 \pm 1.6$ & 147.8 & +3.3 \\
\hline $\mathrm{Yb}_{2}\left(\mathrm{SO}_{4}\right)_{3} \cdot 8 \mathrm{H}_{2} \mathrm{O}$ & 9.978 & -1.937 & $80.32 \pm 0.9$ & 79.62 & +0.8 \\
\hline \multicolumn{6}{|c|}{$E_{x}=8.907 \mathrm{keV}$} \\
\hline $\mathrm{Nd}_{2}\left(\mathrm{SO}_{4}\right)_{3} \cdot \mathrm{H}_{2} \mathrm{O}$ & 7.126 & 1.781 & $140.2 \pm 1.6$ & 137.2 & +2.2 \\
\hline $\mathrm{Eu}_{2}\left(\mathrm{SO}_{4}\right)_{3} \cdot \mathrm{H}_{2} \mathrm{O}$ & 7.612 & 1.295 & $168.4 \pm 1.8$ & 157.8 & +6.7 \\
\hline $\mathrm{Tb}_{2}\left(\mathrm{SO}_{4}\right)_{3} \cdot \mathrm{H}_{2} \mathrm{O}$ & 8.252 & 0.655 & $193.4 \pm 2.0$ & 171.6 & +12.7 \\
\hline $\mathrm{Yb}_{2}\left(\mathrm{SO}_{4}\right)_{3} \cdot \mathrm{H}_{2} \mathrm{O}$ & 9.978 & -1.071 & $59.76 \pm 0.8$ & 60.97 & -1.6 \\
\hline \multicolumn{6}{|c|}{$E_{x}=13.347 \mathrm{keV}$} \\
\hline $\mathrm{Nd}_{2}\left(\mathrm{SO}_{4}\right)_{3} \cdot \mathrm{H}_{2} \mathrm{O}$ & 7.126 & 6.221 & $47.21 \pm 0.5$ & 46.89 & +0.8 \\
\hline $\mathrm{Eu}_{2}\left(\mathrm{SO}_{4}\right)_{3} \cdot \mathrm{H}_{2} \mathrm{O}$ & 7.612 & 5.735 & $55.43 \pm 0.6$ & 54.62 & +1.5 \\
\hline $\mathrm{Tb}_{2}\left(\mathrm{SO}_{4}\right)_{3} \cdot \mathrm{H}_{2} \mathrm{O}$ & 8.252 & 5.095 & $59.01 \pm 0.7$ & 59.84 & -1.3 \\
\hline $\mathrm{Yb}_{2}\left(\mathrm{SO}_{4}\right)_{3} \cdot \mathrm{H}_{2} \mathrm{O}$ & 9.978 & 3.369 & $75.23 \pm 0.6$ & 74.81 & +0.5 \\
\hline
\end{tabular}

$\mathrm{PD}=$ Percent difference $=[($ Experimental mean $\mu / \rho-$ Computed $\mu / \rho) /$ Computed $\mu / \rho] \times 100$ 


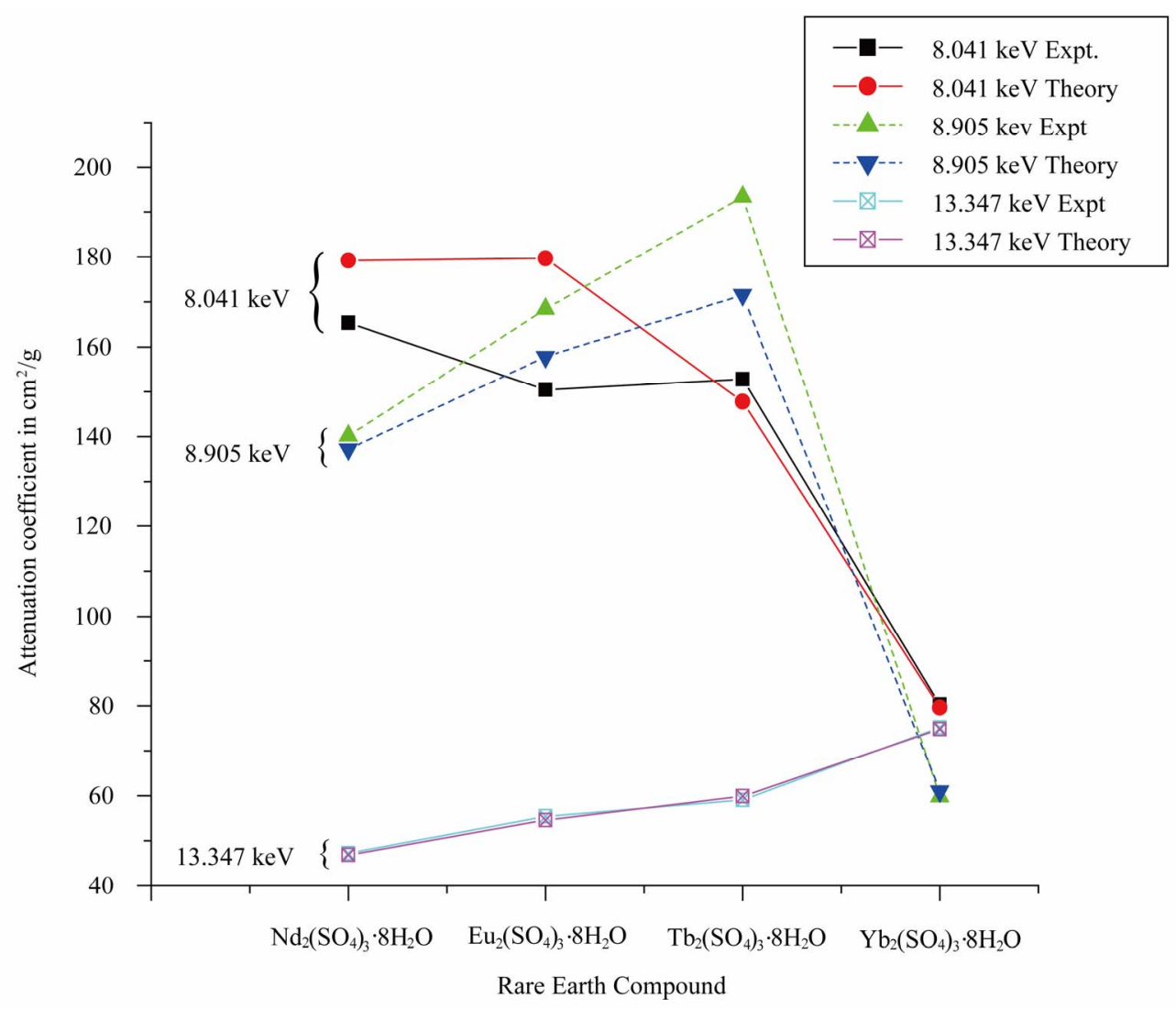

Figure 2. Experimental and Theoretical estimated values of mass attenuation coefficient of rare earth sulphates.

coefficient between the experimental and theoretical by $6.7 \%$, and $12.7 \%$ respectively. Thus mixture rule cannot be applicable for the rare earths compounds where $L$ edge energy is close to the incident photon energy. This deviation is also shown in Figure 2 by plotting mass attenuation coefficient (Experimental and Theoretical) Vs rare earths compound. The experimental and theoretical mass attenuation coefficient value for Neodymium and Europium sulphates at 13.347 shows a good agreement within the $2 \%$ and other hand the same compound at 8.041 and $8.907 \mathrm{keV}$ shows a deviation with theoretical value. This results purely the mixture rule can't be applicable in both the cases otherwise it can be applicable provided that the edge effects/chemical effects are taken into account.

In the Table 2 effective atomic number are estimated using the least squares formula by ploting the mass attenuation coefficient versus the elements for each energies. From the said graph the estimated value of effective atomic number of the dosimetric materials found to vary from $10 \%$ to $18 \%$ for all the suphides. The theoretical values of the $Z_{\text {eff }}$ are also calculated using the formula given by Jackson and Hawkes [1] and these values are discussed in the light of the dosimetry point of view and as discussed in the introduction. The experimental
Table 2. Determined and estimated values of effective atomic number and electron density of the rare earths compounds.

\begin{tabular}{|c|c|c|c|}
\hline \multirow{2}{*}{$\begin{array}{c}\text { Name of the } \\
\text { Sample }\end{array}$} & \multicolumn{2}{|c|}{ Effective Atomic Number $\left(Z_{e f f}\right)$} & \multirow{2}{*}{$\begin{array}{l}\text { Electron Density } \\
N_{\mathrm{e}}\left(10^{24} \mathrm{elec}^{-1}\right)\end{array}$} \\
\hline & Expt & Jackson 1981 & \\
\hline \multicolumn{4}{|c|}{$8.041 \mathrm{keV}$} \\
\hline $\mathrm{Nd}_{2}\left(\mathrm{SO}_{4}\right)_{3} \cdot 8 \mathrm{H}_{2} \mathrm{O}$ & 48.14 & 41.41 & 1.649 \\
\hline $\mathrm{Eu}_{2}\left(\mathrm{SO}_{4}\right)_{3} \cdot 8 \mathrm{H}_{2} \mathrm{O}$ & 46.58 & 43.79 & 1.562 \\
\hline $\mathrm{Tb}_{2}\left(\mathrm{SO}_{4}\right)_{3} \cdot 8 \mathrm{H}_{2} \mathrm{O}$ & 46.83 & 45.63 & 1.542 \\
\hline $\mathrm{Yb}_{2}\left(\mathrm{SO}_{4}\right)_{3} \cdot 8 \mathrm{H}_{2} \mathrm{O}$ & 37.37 & 49.91 & 1.185 \\
\hline \multicolumn{4}{|c|}{$8.907 \mathrm{keV}$} \\
\hline $\mathrm{Nd}_{2}\left(\mathrm{SO}_{4}\right)_{3} \cdot 8 \mathrm{H}_{2} \mathrm{O}$ & 45.44 & 41.41 & 1.557 \\
\hline $\mathrm{Eu}_{2}\left(\mathrm{SO}_{4}\right)_{3} \cdot 8 \mathrm{H}_{2} \mathrm{O}$ & 48.45 & 43.79 & 1.625 \\
\hline $\mathrm{Tb}_{2}\left(\mathrm{SO}_{4}\right)_{3} \cdot 8 \mathrm{H}_{2} \mathrm{O}$ & 50.87 & 45.63 & 1.674 \\
\hline $\mathrm{Yb}_{2}\left(\mathrm{SO}_{4}\right)_{3} \cdot 8 \mathrm{H}_{2} \mathrm{O}$ & 37.69 & 49.91 & 1.196 \\
\hline \multicolumn{4}{|c|}{$13.347 \mathrm{keV}$} \\
\hline $\mathrm{Nd}_{2}\left(\mathrm{SO}_{4}\right)_{3} \cdot 8 \mathrm{H}_{2} \mathrm{O}$ & 31.02 & 41.41 & 1.063 \\
\hline $\mathrm{Eu}_{2}\left(\mathrm{SO}_{4}\right)_{3} \cdot 8 \mathrm{H}_{2} \mathrm{O}$ & 32.82 & 43.79 & 1.101 \\
\hline $\mathrm{Tb}_{2}\left(\mathrm{SO}_{4}\right)_{3} \cdot 8 \mathrm{H}_{2} \mathrm{O}$ & 33.55 & 45.63 & 1.104 \\
\hline $\mathrm{Yb}_{2}\left(\mathrm{SO}_{4}\right)_{3} \cdot 8 \mathrm{H}_{2} \mathrm{O}$ & 36.53 & 49.91 & 1.159 \\
\hline
\end{tabular}


and theoretical $Z_{\text {eff }}$ values are agreeing within 5\% except the edge region. It is important to mention that the theoretical/calculated values have not considered the edge effects and since the effective atomic numbers are under/over estimated when any element falls below the absorption edge.

In the present work, there is a good indication that even in the low photon energy region say that up to $15 \mathrm{keV}$ the effective atomic number can be determined with greater accuracy but one should take into account of edge effects. The electron density of the dosimetric materials is calculated using the experimental $Z_{\text {eff }}$ values and found to vary 0.478 to $0.676\left(10^{24}\right.$ electrons $\left.g^{-1}\right)$. In conclusion, the determined $Z_{\text {eff }}$ value is agreeing with the theoretical values within $5 \%$ at this energy range and one should also take care of effects if high atomic number dosimeters are involved.

\section{ACKNOWLEDGEMENTS}

One of the authors BRK is expressed sincere thanks since this work is financially support by UGC New Delhi.

\section{REFERENCES}

[1] Jackson, D.F and Hawkes, J.D. (1981) X-ray attenuation coefficients of elements and mixtures. Physics Reports,
70, 169. doi:10.1016/0370-1573(81)90014-4

[2] Nagabhushan, N.M., Kerur, B.R., Lagare, M.T., Nathuram, R., Abani, M.C., Thontadarya, S.R. and Hanumaiah, B. (2004) Technique for measurement of photon intensity for the determination of $\mu$ in the low photon energy region. Journal of X-Ray Science and Technology, 12, 161-168.

[3] Rose, E.M. and Shapiro, M.M. (1948) Statistical error in absorption experiments. Physical Review A, 74, 18531864. doi:10.1103/PhysRev.74.1853

[4] Pearson, J.J. and Osborne, R.R. (1960) Practicle nucleonics; a course of experiments in nuclear physics. E \& F.N. Spon, London.

[5] Sharnabasappa, K.B.R., Anilkumar, S. and Hanumaiahm, B. (2010) Determination of X-ray mass attenuation coefficients using HPGe detector. Applied Radiation and Isotopes, 68, 76-83. doi:10.1016/j.apradiso.2009.08.004

[6] Kerur, B.R., Thontadarya, S.R. and Hanumaiah, B. (1993) Measurement of x-ray mass attenuation coefficients using mixed radiation emitters. Indian Journal of Physics, 67, 163.

[7] Gerward, L., Guilbert, N., Jensen, K.B. and Levring, H. (2001) X-ray absorption in matter Reengineering XCOM. Radiation Physics and Chemistry, 60, 23-24. doi:10.1016/S0969-806X(00)00324-8

[8] Kortright, J.B. (1986) Characteristic X-ray energies, X-ray data booklet. In: Vaughan, D. Ed., Lawrence Berkeley Laboratory, University of California, Berkeley. 